\title{
TODOROV, SAID Y EL DIÁLOGO CON EL HUMANISMO
}

\section{TODOROV, SAID AND THE DIALOGUE WITH THE HUMANISM}

\author{
Sergio García Guillem ${ }^{1}$ \\ Université Paris VIII
}

Recibido: 17-1-2016

Aceptado: 6- 5- 2016

Resumen: Tanto el pensador franco-búlgaro, Tzvetan Todorov, como el activista palestino-americano y profesor universitario, Edward W. Said, mantuvieron hasta la muerte de este último una rica amistad que trasciende cualquier vicisitud teórico-práctica entre ambos. En este caso concreto, después de indagar en este (des)encuentro amistoso, se intentará analizar y comparar la herencia humanista en algunas de las obras y artículos de ambos pensadores con el fin de aportar algo de claridad frente a nuestra más próxima actualidad.

Palabras clave: Edward Said; Tzvetan Todorov; humanismo; antropología; democracia; resistencia.

\begin{abstract}
The Franco-Bulgarian thinker, Tzvetan Todorov, and the palestinian-american activist and professor, Edward W. Said, maintained until the death of the latter a rich friendship that transcends any theoretical and practical thinking variations between them. In this case, after investigate in this friendship (dis)agreement, we will try to analyze and compare the humanist inheritance in some of the works or papers of both thinkers to, in some way, give some clarity in front of our nearest actuality.
\end{abstract}

Keywords: Edward Said; Tzvetan Todorov; humanism; anthropology; democracy; resistance.

1.. (s.garcia@latorredelvirrey.es) Estudiante en el Máster «Philosophie et Critiques Contemporaines des arts et de la culture» ("Filosofía y Críticas Contemporáneas del arte y de la cultura"). Licenciado en Filosofía por la Universidad de Valencia y jefe de redacción de la sección de Estudios franceses en la revista La Torre del Virrey. Instituto de Estudios Culturales Avanzados. Sus intereses principales se centran en el pensador franco-rumano, Emil Cioran, las relaciones entre filosofía y literatura, la estética cinematográfica y la antropología filosófica. 
«[...] En suma, desde pequeño, mi relación con las palabras, con la escritura, no se diferencia de mi relación con el mundo en general. Yo parezco haber nacido para no aceptar las cosas tal como me son dadas.»

\section{Julio CoRTÁzAR, La isla a mediodía (1966)}

\section{Introducción}

En el segundo de los volúmenes reunidos por Tzvetan Todorov en el año 2009, una selección de pequeños ensayos titulada Vivre seuls ensemble. La signature humaine ${ }^{2}$, publicados a partir de 1983 y dedicados a la memoria de célebres pensadores como Rousseau, Constant, Stendhal, Beckett o Goethe, el pensador franco-búlgaro dedica un emotivo y sincero capítulo a la memoria de un amigo, a saber, el profesor de literatura comparada en la Universidad de Columbia (USA), Edward W. Said. El propio Todorov comenta ya en el prólogo a la mencionada obra como «el retrato de Edward Said en primer plano recuerda la contribución de este gran intelectual contemporáneo al estudio del encuentro entre culturas» ${ }^{3}$. Si como afirma Todorov existe un punto de encuentro y diálogo entre ambos pensadores, éste parece encontrarse en los albores de la crítica literaria, el reconocimiento de la alteridad, la cuestión del exilio, del «homme dépaysé» ${ }^{4}$, y finalmente la pertenencia a una familia de corte humanista ${ }^{5}$. El objetivo de Todorov en este ensayo, a través tanto de esta serie de pensadores como de su fiel compañero y amigo, parece una tentativa de comprender con claridad — cualesquiera que sean los ángulos de aproximamiento, las generalidades o el camino seguido-, la condición y las plurales conductas humanas. Acercándose ante todo «al análisis de nuestros actos sociales, de nuestros regímenes políticos, del encuentro entre culturas, pero también

2.. Cf. Todorov, T.: L'Expérience totalitaire. La signature humaine I. Paris: Points Essais, 2011. Vivre seuls ensemble. La signature humaine II. Paris: Points Essais, 2012. A partir de este momento, todas las traducciones serán ofrecidas por el autor del texto.

3.. Cf. Vivre seuls ensemble, p. 13.

4.. El concepto en lengua francesa podría traducirse al castellano como el "hombre desplazado", "hombre desfamiliarizado" o incluso como el "hombre desarraigado".

5.. "Si hiciera falta buscarle una familia ideológica, no sería, a pesar de las afinidades, ni el marxismo ni el posestructuralismo a la moda en las universidades americanas (la French Theory), sino el humanismo - a condición de que éste sea realmente universal y cese de confundirse con el eurocentrismo [...]» (Cf. Todorov T.: « Edward Saïd, le spectateur exilé » en Le Monde des Livres, mai 2008).

Thémata. Revista de Filosofía №54 (2016) pp.: 265-280. 
de nuestra capacidad de imaginar obras, sentido, ideales, una espiritualidad, una continuidad temporal [...] un $\operatorname{cosmos} »^{6}$.

Al final de este magnífico prólogo, Todorov revisa una parte muy destacada de su carrera profesional, desde su llegada a la capital francesa con los inicios estructuralistas, sobre todo con el magisterio de Roland Barthes, o el inicio en el campo de la crítica literaria y la antropología social y cultural, con obras como Mikhaïl Bakhtine. Le principe dialogique (1981), La Conquête de l'Amérique: la Question de l'autre (1982) o Nous et les autres. La reflexion française sur la diversité humaine (1989). Este último ensayo formará parte de una posterior etapa de madurez donde el debate parece enriquecerse a través de otras ópticas, a saber, una positiva y crítica admiración por determinadas corrientes contemporáneas de la historia del arte, pero también, un interés socio-político por los avatares del comunismo, el totalitarismo o los campos de concentración. Finalmente, su condición de exiliado, como ocurrirá en los últimos años del profesor Said, le hará repensar su autobiografía política, plasmada en un detallado y emotivo ensayo, L'Homme dépaysé (1998). A partir de este segundo periodo de interés por cuestiones antropológicas, también en el campo de la autobiografía, Todorov recurrirá a la persona de Edward Said. Como acaba comentando en el mencionado prólogo:

\footnotetext{
El retrato de Said [...] está puesto a parte ya que Said pertenecía a la misma generación que yo; éramos amigos, a pesar de que nos viésemos irregularmente. Aunque nuestras historias fuesen diferentes, me sentía cercano a su reflexión sobre la diferencia de culturas y sobre los efectos del exilio. Este retrato se ha vuelto una especie de introducción autobiográfica al computo del libro ${ }^{7}$.
}

El diálogo que mantienen las obras de ambos pensadores, a pesar de sus posibles diferencias, nos acercará, en un primer momento, a ese fructuoso encuentro entre ambos pensadores. Posteriormente, en un segundo lugar, intentaremos esclarecer una mejor concepción del humanismo contemporáneo; corriente - o familia - en la cual, a través de una revisión de la historia del pensamiento en el caso de Todorov, y un análisis contemporáneo de la situación del intelectual, las humanidades y el panorama socio-político en Said, parecen encontrarse ambas direcciones. Estas posiciones abocan finalmente hacia un humanismo democrático y temperado pero, al mismo tiempo, crítico y resistente. Sin más demora, empecemos comprobando el diálogo entre ambos pensadores y sus aportaciones a terrenos tan fecundos como la historia de las ideas, la antropología y la crítica literaria.

6.. Cf. Vivre seuls ensemble, pp. 13-14.

7.. Ídem.

Thémata. Revista de Filosofía N54 (2016) pp.: 265-280. 


\title{
II. Deux hommes dépaysés. Todorov, lector de Said
}

\begin{abstract}
[...] Como intelectual humanista, Said está preparado para desafiar los poderes imperantes y los consensos establecidos en nombre de una adhesión intransigente a los valores universales. Al mismo tiempo, él sabe ser un ferviente admirador [...] Pensador brillante, Said era de igual modo un hombre generoso y caluroso, inolvidable para todos aquellos que lo han conocido. ${ }^{8}$
\end{abstract}

La admiración de Todorov por su buen amigo proviene de esa curiosidad infatigable y ese compromiso humanista del que tanto profesaba Said. En estas breves páginas se eleva toda una oda a la persona y la carrera del profesor. Todorov cuenta así detalladamente su primer encuentro con Said:

Me es difícil hablar de la obra de Edward Said como de un tema de estudio entre otros, ya que en vida una amistad de más de treinta años me ligaba con él. Lo encontré en los años setenta en la Universidad de Columbia en Nueva York [...] yo daba un curso en el departamento de literatura comparada donde enseñaba Said. Debí conocerlo en 1974 [...] Teníamos algunos rasgos en común que podían acercarnos [...] ${ }^{9}$

Todorov repasa minuciosamente en estas páginas la carrera de Said, deteniéndose simultáneamente en los aspectos teóricos del intelectual que más le interesaban y que guardan relación con el hilo conductor de sus propios ensayos. Sus biografías se acercan íntimamente en una característica común: su situación de inmigrantes. Todorov desde la Bulgaria comunista hasta París, y Said desde la represión en Palestina y Egipto hasta Nueva York. Por esta condición de exiliados, y en ello inciden ambos autores, los inmigrantes tienen personalidades todavía más plurales que las de los habitantes de un país, ya que ellos mismos «conocen la ruptura entre un antes y un después. Pero cada uno vive esta pluralidad a su forma $»^{10}$. El ojo crítico del Todorov que repasa la trayectoria intelectual y activa de Said se entremezcla con el trato a ese individuo en su condición de amigo ("Said tenía los pies sobre la tierra, también el cuerpo, y noo buscaba ignorarlo. Era igualmente un hombre generoso y apasionado, ferviente admirador pero también un acervo crítico») ${ }^{11}$. Ambos, como confirma el propio Todorov, se fueron acercando a la promoción del aproximamiento "estructuralista" y "semiótico". Esta dirección teórica permitió un mejor análisis de los textos literarios, pero dejando de lado, y es un factor destacado que tanto Todorov como Said reivindicarán, la función del mundo. Muy a

\footnotetext{
8.. Cf. «Edward Saïd, le spectateur exilé ».

9.. Cf. Vivre seuls ensemble, pp. 17-18.

10.. Ídem, p. 19.

11.. Ídem, p. 21.
}

Thémata. Revista de Filosofía Nº54 (2016) pp.: 265-280. 
priori, Said intentaba no entremezclar sus clases de literatura inglesa y comparada, dentro de la revisión crítica de diferentes textos occidentales, con sus ideales políticos y su defensa del pueblo palestino. Todorov encuentra a Said en este momento concreto de unión idiosincrática, sobre todo en los albores de la publicación de Orientalismo (1978):

El objetivo era más radical. Consistía en decir que "Oriente" tan sólo existía como fabricación, una ficción creada por los occidentales [...] Las nociones de "Oriente" o de "oriental" no provienen de una generalización de hechos observados en una parte del mundo sino, más bien, de una necesidad europea de cosificar fuera de ellos su "otredad" al mismo tiempo que centro de atracción exótica... ${ }^{12}$

El discurso que tiene como objeto el Oriente nos alecciona, no única y exclusivamente sobre el mundo oriental, sino de igual manera sobre sus autores, a saber, los mismos occidentales. Las identidades nacionales o étnicas no quedan impermeables a ninguna clase de mezcla, como afirma Todorov. El profesor y activista, en palabras del pensador franco-búlgaro, «descubre además que esta experiencia, lejos de ser excepcional, encarna uno de los rasgos característicos del mundo moderno: la aceleración de los contactos entre culturas, el carácter cambiante de éstas, la pluralidad interior de cada identidad. El orientalismo es una construcción artificial, pero resulta igual para el occidentalismo respaldado por los enemigos de Occidente. Es por esto que Said se vuelve un adversario decidido de la tesis del 'choque de civilizaciones' $»^{13}$. Ante la publicación del ensayo de Said, el propio Todorov sugerirá a la editorial francesa Seuil la traducción y publicación de esta obra. La edición francesa de L'Orientalisme: l'Orient créée par l'Occident (1980) vendrá acompañada del prólogo del propio Todorov en homenaje a su amigo, quien, en cierta forma de agradecimiento, publicó también en 1993, en la edición inglesa, el ensayo de Todorov, On Human Diversity: Nationalism, Racism and Exoticism in French thought ${ }^{14}$.

A pesar de las similitudes biográficas entre ambos pensadores, Todorov recalca, sobre todo en el terreno de la política, muchos de los puntos que los separan. El pensador franco-búlgaro siempre consideró, sobre todo a través de la lectura de Orientalismo y de Cultura e Imperialismo (1993), como «el adversario principal se llamaba para él [Said], imperialismo, europeo o americano; para mí [Todorov], totalitarismo, comunismo o nazismo» ${ }^{15}$. Todorov es, desde su juventud, un ferviente y atento lector de muchas de

12.. Ídem, p. 24.

13.. Cf. «Edward Saïd, le spectateur exilé».

14.. Cf. Todorov, T.: On Human Diversity: Nationalism, Racism and Exoticism in French thought, trans. Catherine Porter, ed. Edward W. Said, Cambridge: Harvard University Press, 1993.

15.. Cf. Vivre seuls ensemble, p. 27.

Thémata. Revista de Filosofía No54 (2016) pp.: 265-280. 
las tesis de Vassili Grossman, Raymond Aron o Mikhail Bakhtine, mientras que Said es un seguidor de personalidades como Michel Foucault, T.W. Adorno o Erich Auerbach. El profesor de literatura comparada, a través de estos interlocutores, buscaba a quién dirigirse, en qué momento y situaciones determinadas; mientras el pensador franco-búlgaro volvía al trabajo de campo con una maleta hermenéutica repleta de recursos. Said siempre estuvo en vida activamente comprometido en un combate político (sobre todo, como indica Todorov, el del Estado palestino). El profesor de literatura comparada necesitaba del reconocimiento de su causa. La principal amenaza, al igual que en el caso de Todorov, no provenía del hecho de volver a sus tierras natales, sino que ésta deriva esencialmente del propósito de perseverar y luchar por una identidad. Factor identitario que se lanza al campo de batalla en contra de toda injusticia histórica, sobre todo con determinados pueblos y países en cierta manera olvidados por la historia ${ }^{16}$. Sin embargo, a lo largo de su carrera en EEUU, Said hizo numerosos enemigos debido a todas sus declaraciones de prensa en forma de artículos o entrevistas con los medios. Algunos colectivos integristas llegaron a amenazarlo o, incluso, a incendiarle su despacho en la universidad de Columbia. A pesar de todas estas diatribas, y alejándonos del territorio político que une y distancia a ambos pensadores, el espíritu de compromiso saidiano era bastante moderado. Él mismo, como se puede comprobar en sus entrevistas y declaraciones, sabía que la acción política consiste esencialmente en reconciliar "intereses divergentes", como igualmente los califica Todorov, pero exigiendo ante todo un férreo compromiso éticopolítico.

En cuanto a la formulación de la tarea contemporánea del intelectual y su posición ante el exilio, Said dedicará uno de sus ensayos tardíos a esta cuestión: Representaciones del intelectual ${ }^{17}$. En la definición de esta tarea vuelven a encontrarse ambos amigos al defender la figura del intelectual como la de un individuo que, en palabras de Todorov, no acaba conformándose con ser un simple especialista en un campo concreto, sino que interviene directamente en el espacio público. El intelectual se distinguirá por ser aquél que habla, se auto-margina y se enfrenta al mundo ${ }^{18}$. Como bien recuerda Todorov en su lectura, Said siempre fue un intelectual comprometido con su causa socio-política, también con el laicismo y un

16.. "Las simpatías personales de Said se acercaban a un Estado laico y no étnico en el conjunto de los territorios israelitas y palestinos [...] Admitía la necesidad de crear desde un principio un Estado palestino soberano" (Ídem, p. 30).

17.. Cf. Said, E., Representations of the Intellectual, New York: Viking Press, 1994 (edición española del 2007).

18.. "[...] es, además, aquel que, lejos de sumirse al servicio incondicional de un poder o de una causa, preserva su independencia y se reclama libre la búsqueda de la verdad y de los valores que él mismo estaría listo para asumir personalmente" (Cf. Vivre seuls ensemble, p. 34).

Thémata. Revista de Filosofía No54 (2016) pp.: 265-280. 
gran adversario de toda forma de nacionalismo. En este espectro de marginación, Said establece un vínculo entre los intelectuales y los exiliados, ya que el exilio podría conducir a un estado de espíritu concreto, el saberse y comprenderse esencialmente como auténticos «hommes dépaysés». Este tipo de individuo, en palabras de Todorov, no renuncia necesariamente a su antigua identidad (antes de la llegada a un país, la adopción de una lengua extranjera o incluso de las costumbres vecinas) sino que participa simultáneamente en ambos marcos de referencia, sin identificarse con ninguno, fomentando de este modo la mirada crítica sobre el nuevo entorno que les rodea («[...] portadores de identidades múltiples, nosotros podemos vivirlo cambiando de provincia, de medio, de profesión o de sistema de valores; simplemente, el exilio es la forma emblemática de toda "transculturación"») ${ }^{19}$. En este mismo punto Todorov comienza a entrever algunas de las premisas humanistas del propio Said. Y comenta : «en efecto, para Said, el humanismo no se definía por el hecho de que somos capaces de abrirnos a la universalidad, a todas las culturas del mundo, más que a privilegiar la suya propia, en una ceguera etnocéntrica ${ }^{20}$. La tarea del humanista, como defiende Said, no es la de ocupar un puesto concreto - como en el caso del intelectual-, ni de pertenecer a una región geográfica concreta, sino que se encuentra, al mismo tiempo, dentro y fuera en relación a las ideas y los valores que circulan tanto en nuestra sociedad como en otras sociedades. Este rasgo característico de ambas personalidades es el que lleva al pensador franco-búlgaro a la redacción de L'Homme dépaysée, y de igual modo, el que impulsa a Said en 1999, y años posteriores al conocimiento de su fatídico destino, a la publicación de su propia autobiografía titulada Fuera de lugar ${ }^{21}$.

El legado humanista de Said parece residir en esta producción tardía, que se inicia con el giro circunstancial hacia el recuerdo autobiográfico. Como recuerda Todorov: «si hace falta buscar la familia ideológica por la que Said se sentía más cercano, no sería, aunque con algunas afinidades, ni el marxismo ni el nietzscheanismo a la moda en las universidades americanas [...] sino el humanismo ${ }^{22}$. Su crítica mirada se abría así a un espacio universal en la difusión del saber y la defensa de todos los derechos que engloban a la humanidad, sin caer en algunos de los reduccionismos filológicos e históricos que ya había logrado diseccionar a partir de Orien-

19.. Ídem, p. 36.

20.. Idem.

21.. «[...] es en este libro donde Said llega a ofrecer la imagen más detallada e inteligible de su ser: llega a juntar, no sólo su condición histórica de Palestino exiliado y sus intereses profesionales por el análisis de texto [...] Con la lectura de Fuera de lugar, entendí que una herida incurable manchaba esta relación esencial para Said, un amor que él mismo vivía sin reciprocidad" (Cf. Vivre seuls ensemble, pp. 38-39).

22.. Ídem, p. 41.

Thémata. Revista de Filosofía №54 (2016) pp.: 265-280. 
talismo. Él mismo sabía, apunta Todorov, que los derechos humanos no eran un mero efecto del discurso dominante, o de todo supuesto epistemológico imperante, sino un rico y plural fruto de toda corriente humanista. Dicho proyecto humanista resultaba para Said una vía de escape ante un sistema lingüístico que acaba reprimiendo, por utilizar la formulación todoroviana, a un nosotros y unos otros:

\begin{abstract}
el especialista en humanidades o en ciencias sociales que se reclama desde una postura humanista debe ser, por una parte, un buen conocedor de los textos. Pero, por otra parte, no debe jamás olvidar el marco bajo el cual esos textos han sido producidos y recibidos. No se dejó nunca llevar de las palabras a las cosas, o de las cosas a las palabras. ${ }^{23}$
\end{abstract}

Sucederá una experiencia casi similar en el caso de Todorov, inmiscuido desde juventud en los textos formalistas y estructuralistas, pero sospechando posteriormente de la falta de aplicación práctica de éstos en la esfera pública. Pasando posteriormente en una segunda etapa de su vida a un profundo recorrido y análisis de la conquista americana del siglo $\mathrm{XV}$, junto a problemas cruciales en el ámbito de la antropología en muchas de sus obras. Said tampoco deseaba permanecer en el estricto análisis de los textos literarios y la labor de la literatura comparada, sino que deseaba ante todo ligar estas ricas comparaciones con la experiencia humana. El intelectual humanista, lector de la gran pluralidad literaria y humana, debe ser un transgresor de fronteras, aprovechando el ser hijo de un exilio — o un "desplazamiento"-, potenciando de esta manera su ligadura con una realidad que lo acecha constantemente, con un público que lo lee o lo escucha y, ante todo, llevando las ideas ya pensadas, en una línea muy adorniana, hacia la eterna victoria:

Por la forma en la que Said vivió los últimos años de su vida, queda toda una obra [...] Said había conseguido a llegar más allá de su yo anterior, a esperar y decir la verdad de su ser, a esculpir su existencia como una obra. Se volvió un individuo universal, un ser particular cuyo destino, interpretado por él mismo, interpela a todo individuo [...] Pero nosotros podemos pensar en él, en el esfuerzo que cumplió consigo mismo y que tuvo como efecto el volver el mundo un poco más bello y rico en sentido. Por todo ello, Edward Said merece nuestra más sincera gratitud. ${ }^{24}$

\title{
III. El diálogo con el humanismo
}

Retomando el propósito de nuestro acercamiento a las posiciones de Todorov y Said, el escritor y periodista iraquí, Tariq Ali subraya una

23.. Ídem, pp. 41-42.

24.. Ídem, pp. 44.45.

Thémata. Revista de Filosofía №54 (2016) pp.: 265-280. 
de las respuestas formuladas por Edward Said en una de sus entrevistas más personales:

Y lejos de intentar llevar razón, lo que opino es que es importante ser crítico. Y yo he sido siempre crítico [...] Yo me considero a mí mismo un agitador [...] ¡Yo agito contra mí mismo! [...] en Occidente he sido o bien ignorado por muchos de los supuestos marxistas que son también críticos literarios, o bien atacado por mi liberalismo, por mi humanismo vestigial. ${ }^{25}$

Estas palabras muestran el terrible anhelo de reflexionar acerca de todo lo humano allá donde se encuentre, potenciando incondicionalmente el verdadero autoconocimiento que se conforma de pequeñas piezas de autocrítica, y que confirmarán en cierta manera, los horizontes del humanismo. La idea saidiana de humanismo, muy en sinfonía con las tesis ya defendidas en Orientalismo, apuesta por la tesis de que "las culturas coexisten e interaccionan de un modo muy fructífero en una proporción mucho mayor de lo que combaten entre sí. Es a esta idea de cultura humanística como coexistencia y comunidad compartida a lo que pretenden contribuir estas páginas" ${ }^{26}$. La toma de contacto saidiana con el humanismo ronda de este modo el conocer qué tipo de relaciones mantiene esta "familia", por mantener la terminología todoroviana, con el quehacer público del intelectual. Es así como la crítica y la exposición saidiana versarán, no sólo acerca de esta familia de pensamiento, sino estrechando sus lazos con grandes familias como la filología, la crítica literaria o la propia historia político-social ${ }^{27}$.

Comencemos pues con la posición que sobre la cuestión del humanismo mantiene Edward Said. A través de un completo y elaborado capítulo dedicado a la memoria de la tarea del humanismo, y más concretamente, en la labor de las actuales "humanidades", Said señala como el impacto de estructuralismo y el post-estructuralismo francés dio lugar a una "derrota contundente" de lo que se llegó a considerar como el "humanismo tradicional", al profetizar la muerte del sujeto - y por ende del autor- en pensadores tales como Foucault o Lévi-Strauss. El clima de la intelectualidad francesa en plena segunda mitad del siglo XX resulta para estos autores claramente anti-humanista (también la Alemania —y la Francia- lectora de la Carta sobre el humanismo (1947) de Heidegger). Said esgrimirá hacia

25.. Cf. Ali, T.: Conversaciones con Edward Said, trad. Natalia Rodríguez Martín, Madrid: Alianza ed., 2010, pp. 50, 63, 75. La cursiva es nuestra.

26.. Cf. Said, E., Humanismo y crítica democrática. La responsabilidad pública de escritores e intelectuales, traducción de Ricardo García Pérez, editorial Debate: Barcelona, 2006, p. 18.

27.. "[...] Lo que me interesa aquí es el humanismo como práctica útil para intelectuales y académico que tratan de averiguar qué están haciendo o cuál es su compromiso como académicos, y cuyo deseo sea vincular estos principios con el mundo del que son ciudadanos" (Ídem, p. 26).

Thémata. Revista de Filosofía N54 (2016) pp.: 265-280. 
el lado contrario: “[...] todavía me parece plenamente vigente la idea afín de que los ideales humanísticos de libertad, crítica, resistencia y aprendizaje proporcionan a la mayor parte de los pueblos desfavorecidos la energía para combatir [...] o al menos para tratar de derrotar al despotismo y la tiranía"28. De este modo, la lección de Said es la de "ser crítico con el humanismo en nombre del humanismo" (su "humanismo como resistencia" reforzará posteriormente esta tesis). El núcleo central del humanismo:

[...] consiste en la idea secular de que el mundo histórico es obra de los hombres y las mujeres, y no de Dios, y que se puede comprender de forma racional [...] únicamente podemos conocer de verdad lo que hacemos; o, dicho de otro modo, que solo podemos conocer las cosas en función del modo en que se llevaron a cabo. ${ }^{29}$

El texto saidiano resulta de una rabiosa actualidad, los residuos negativos que deja la estela del humanismo, y de las "humanidades", son factores imperecederos que resisten en nuestro presente. Las humanidades, como bien afirma Said, parecen haber perdido todo tipo de prestigio e importancia en las universidades. Todas estas disciplinas parecen haber quedado reducidas a una especie de ciencia pseudo-medieval; a pesar de poner de relieve y reactualizar en cierta manera su propio sistema interno a través de nuevas teorías (estudios poscoloniales, los estudios culturales, los queer studies y otras múltiples disciplinas). A pesar de ello, muchas de estas disciplinas caen en la verborrea que parecen volver inocuas las disciplinas humanísticas. Toda la tarea de las humanidades, y del humanista, se ve cercenada por la crítica, pero su tarea debería consistir en un proceso plenamente democrático que diera lugar a una mentalidad cada vez más crítica con los demás, pero también consigo misma ${ }^{30}$. El humanismo consiste, de igual forma, en una pre-comprensión de la democracia, abierta a toda clase social, y muy en consonancia con una actitud reveladora, autocrítica y liberadora. Said intenta concluirlo en muchas ocasiones con la expresión: "el humanismo es crítica". Una crítica dirigida a toda institución académica, a toda forma de gobierno, y a todos los ámbitos de la cultura: desde las ciencias positivas, pasando por la literatura, la filosofía o la filología. Esta comprensión del humanismo reside también en afirmar que en el mundo existen otras tradiciones de conocimiento, otras culturas. El humanismo, y aquí Said se encuentra con Todorov, resulta también padre de cierta concepción de la antropología. El fenómeno de auto-comprensión y

28.. Ídem, p. 30.

29.. Ídem, p. 31.

30.. "Said asume una identidad bicultural y móvil, que se aleja de todo estereotipo, que en la perspectiva de un intelectual crítico interactúa y se pasea por Occidente y Oriente sin complejos de culpa ni de superioridad" (Cf. Subercaseaux, B.: "Edward Said: desde su biografía a su postura intelectual" en Revista Universum, n 20, Vol. 1 : 168 - 173, 2005, p. 170).

Thémata. Revista de Filosofía No54 (2016) pp.: 265-280. 
autorrealización occidental se ve atravesado por el encuentro con la alteridad $^{31}$. El humanismo es, de igual modo, una continua revisión de aquellos férreos presupuestos que la tradición lega violentamente ("todo documento de cultura es un documento de barbarie" como ya señaló W. Benjamin y continuará reivindicando Said). El mundo se complejiza cada vez más, discurriendo en su epicentro corrientes contradictorias, ideologías dispersas en un presente cada vez más confuso con incesantes terremotos geopolíticos que alteran constantemente el sentido - y el poder- de la tarea del intelectual y que ponen voz al grito casi ahogado del humanismo. Significa ante todo el hecho de:

situar la crítica como forma de libertad democrática y como ejercicio de continua puesta en cuestión y acumulación de un conocimiento abierto a las realidades históricas [...] pienso en un enfoque mucho más intelectual y racional, mucho más riguroso que, como ya he sugerido, se inspira en un concepto bastante preciso de lo que significa leer filológicamente con una mirada mundana e integradora [...] y al mismo tiempo en ofrecer resistencia a las pautas del pensamiento, tan reduccionistas y vulgarizadores, del "nosotros" contra "ellos" típicos de nuestro tiempo. ${ }^{32}$

La función del intelectual humanista del que Said ofrece apología es aquel que intenta desenmascarar y esclarecer con la dialéctica todas las disputas mencionadas, oponiéndose a ellas y desafiando a los silencios impuestos con una postura resistente y crítica, lidiando con los "poderes en la sombra". Hay así una increíble distancia entre "la voluntad de comprender [...] y el deseo de dominar" ${ }^{33}$. La obra de Said, al igual que la de Todorov, intenta de esta manera utilizar la crítica humanística para ampliar todos los campos de batalla, "disolviendo las esposas mentales de Blake para poder pensar de forma histórica y racional, y lograr un conocimiento reflexivo" 34 . Todas las facultades que la escuela de pensamiento humanista nos lega deben seguir manteniendo su crítico status quo, racional y laico; ocupándose esencialmente del mundo de la historia, y no del beneplácito divino. El fármaco saidiano es el de ofrecer una buena dosis de escepticismo crítico que ayude a disipar la niebla totalitaria, nacionalista y etnocéntrica. Resulta, a fin de cuentas, aquello que va surgiendo desde el afuera y que fuerza a lo viviente a tener una relación con su otro, un fármaco

31.. "No puede haber un verdadero humanismo cuyo alcance se vea limitado a ensalzar patrióticamente las virtudes de nuestra cultura, nuestro idioma y nuestras grandes obras. El humanismo es el ejercicio de las propias facultades mediante el lenguaje con el fin de comprender, reinterpretar y lidiar con los productos del lenguaje de la historia, de otros lenguajes y otras historias" (Ídem, p. 49).

32.. Ídem, pp. 69-72.

33.. Cf. Said, E.: "El humanismo como resistencia" en El País, publicado el 23 de agosto de 2003, p.9.

34.. Ídem, pp. 11-12.

Thémata. Revista de Filosofía $\mathrm{N}^{\circ} 54$ (2016) pp.: 265-280. 
sin identidad estable que intenta partir desde la comprensión, la acción y la reacción. Said continuará afirmando todos estos presupuestos con una pluma ya desgastada por el tiempo y la enfermedad, pero que al mismo tiempo le ofrece su última e imperecedera resistencia. Y concluye Said en uno de sus últimos artículos para la prensa escrita: "el humanismo es la única forma de resistencia que tenemos contra las prácticas inhumanas y las injusticias que desfiguran la historia [...]"35.

Desde otra perspectiva, pero no desde una posición muy lejana, Tzvetan Todorov se somete a una entrevista que quedará, a la postre, como el testimonio autobiográfico que no había acabado de perfilar con L'Homme dépaysé. En esta conversación con Catherine Portevin ${ }^{36}$ encontramos a un Todorov mucho más próximo, que pasa desde el relato cotidiano hasta su posición como pensador, antropólogo y teórico de la literatura. La posición todoroviana, deudoras de las tesis universalistas (pero "bien temperadas", como él mismo sentencia a lo largo de toda la entrevista) encuentra su paralelo en señalar hacia el (pos)estructuralismo y el posmodernismo como los deudores de una tradición anti-humanista bastante poderosa en el panorama intelectual francés de los años 60. Frente a este anti-humanismo en boga, "Todorov defendía un humanismo temperado y consciente de sí mismo" ${ }^{37}$. El universalismo que Todorov encuentra en esta tradición —o familia - de pensamiento humanista presenta cierto tipo de moderación al tener en cuenta la heterogeneidad de cada sociedad y sus diferencias. Este argumento encuentra su auge en el ensayo que Todorov dedica en 1998 al problema, a saber, El jardín imperfecto ${ }^{38}$. Como reclama Todorov en la entrevista a propósito de este esclarecedor ensayo:

[...] los primeros humanistas defendían el derecho a valorar una parte del pasado en base a su interés estrictamente humano [...] Proclamaban, ya entonces a su manera, la autonomía de lo humano. Esa autonomía va a tomar dos formas diferentes: importancia del hombre como fuente de sus conocimientos y su acción e importancia del hombre como fin destinario de sus actos. El hombre se convierte en punto de par-

35.. Ídem, p. 15.

36.. Cf. Devoirs et délices. Une vie de passeur. Entretiens avec Catherine Portevin, Paris : ed. du Seuil, 2002 (Deberes y delicias. Una vida entre fronteras, traducción de Marcos Mayer, México: FCE, 2003).

37.. Cf. Groot, G.: "Un humanismo bien temperado. Conversación con Tzvetan Todorov" en Adelante, icontradígame! Filosofía en conversación, traducción a cargo de Catalina Ginard Ferón, Barcelona: ed. Sequitur, 2008, p. 30. La cursiva es nuestra.

38.. Cf. Todorov, T.: Le jardin imparfait. La pensée humaniste en France. Paris: Grasset, 1998.

Thémata. Revista de Filosofía №54 (2016) pp.: 265-280. 
tida y de llegada ${ }^{39}$.

Desde Nosotros y los otros se puede comprobar cómo Todorov acaba reconociéndose dentro del imperfecto jardín de la tradición humanista. A pesar del posible "optimismo ingenuo", del cual se puede acusar a esta corriente de pensamiento, Todorov continúa comentando como el hombre es en realidad presa de iguales fuerzas subterráneas, de pulsiones inconscientes sobre las cuales no tiene ningún control. El humanismo, su familia, no olvida los claroscuros de la condición humana, admitiendo a la postre el siniestro grito de la psique. La tradición humanista es consciente de todo el mal que el individuo puede hacerse a sí mismo y al resto en los periodos más oscuros de la historia ${ }^{40}$. Su idea del individuo es claramente la de un ser "indeterminado" en el plano moral que necesita, en gran parte, del otro para afirmar su existencia y contribuir tanto a su felicidad como a su desgracia (sobre todo desde una conciencia de la corporalidad que atrae constantemente a la finitud y los límites del acto humano). Los individuos son responsables tanto del bien como del mal que pueden producir, tanto desde su individualidad como en el espacio público y social. De aquí que una educación crítica, que privilegie ante todo la libertad, sea un factor relevante para esta tradición de pensamiento. La finitud humana, como sentencia Todorov:

es uno de los grandes temas de los humanistas, pues han renunciado a recurrir a la vida eterna. Sin embargo, no renuncian a la búsqueda de la felicidad, simplemente nos recuerdan su fragilidad. Saben también que nuestra conciencia ha descubierto el infinito; es así que comprendo la condición humana: inadecuación trágica entre nuestra necesidad de infinito y nuestra finitud efectiva, pero también respeto por nuestros intentos por remediarla. ${ }^{41}$

Los humanistas son, de este modo, aquellos que "se rehúsan a admitir que, para preservar la libertad, hay que renunciar a la sociabilidad, a los valores o al yo [el sincronismo del «yo, tú, ellos» de Montaigne]" ${ }^{2}$. El humanismo resulta necesariamente laico, como reivindicaba igualmente Said, pues se rehúsa a buscar otra justificación al amor a los hombres o al individuo. El fin último es el ser humano, ni Dios, ni la armonía cósmica. En la óptica humanista, como sigue señalando el pensador franco-búlgaro, siempre hay vías de fuga ante la determinación, senderos hacia el caos y el misterio de

39.. Cf. Deberes y delicias, p. 162.

40.. "Auschwitz para Primo Levi, Babi Yar y Kolima para Vassili Grossman, la Segunda Guerra Mundial para Romain Gary [...]” (Ídem, p. 166).

41.. Ídem, p. 171.

42.. Ídem, p. 164.

Thémata. Revista de Filosofía Nº54 (2016) pp.: 265-280. 
la libertad ${ }^{43}$. La tradición humanista posee así un marco de referencia. Sin confesar cómo rellenar dichos marcos, nos alecciona a vivir democráticamente, a repensar la democracia como sistema dialogante dentro de cualquier marco político. Partiendo siempre de una sociedad que adjudique igualdad de derechos a sus habitantes, que favorezca la libertad de expresión y que impida volver al temblor de una "industria cultural", de nuevo en un sentido muy adorniano, al caer sometidos como ciegos títeres bajo el invisible control de un Estado maquinal, fraudulento e instrumental ${ }^{44}$.

\section{A modo de conclusión}

Finalizando nuestro recorrido, el pensamiento de esta tradición a la cual Todorov dedica el tiempo y la tinta merece toda atención desde nuestra más próxima actualidad. Su pensamiento permite desembarazarnos de todo automatismo, de las apariencias, penetrando en la profundidad del presente. Todorov, al igual que Said, se preocupa por la fragilidad de las humanidades y la tarea del actual "humanista". Es de este modo como el encuentro entre ambos pensadores resulta actualmente de una gran riqueza en esta rehabilitación del "barco humanista". Todo humanismo es, en su práctica, un humanismo "bien temperado", un humanismo que "para garantizar su supervivencia no teme fijar límites a las libertades y a los derechos absolutos de cada individuo" ${ }^{55}$. Sus acciones en el terreno de esta tradición de pensamiento pasan por el filtro de la palabra. Se escribe, abriendo heridas internas, para actuar sobre el espíritu de los contemporáneos, viviendo todo absoluto en lo cotidiano. Los humanistas, en este sentido, quieren poner en práctica la fuerza de la palabra y la comprensión, la democracia y la libertad, la tolerancia y la razón. El fin de las entrevistas, y de este prolijo diálogo entre dos amigos, adquiere un cariz muy semblante. La pregunta que sigue abierta, y que sigue siendo epicentro existencial del individuo, resulta la misma: ¿cómo vivir?. Para ambos, esta búsqueda toma el camino de las ciencias humanas, de la historia, de

43.. "Es lo que expresa de manera condensada esta fórmula de Montaigne que elegí como título de mi libro, el "jardín imperfecto": la existencia humana es así, el jardín se puede trabajar, pero no habrá de convertirse en el Edén. Existe la perfectibilidad, no la perfección. Es una piedra de Sísifo que se derrumba constantemente, tal es la condición humana: hay que recomenzar siempre, todo debe ser retomado, nada se adquiere definitivamente" (Idem, p. 177).

44.. "El humanismo no da sentido a cada vida individual, no la llena de belleza, pero es eso lo que vale el precio de existir: el contacto con el sentido y la belleza, la comunión entre los seres humanos y la naturaleza [...] Un frágil bote que no podría conducirnos más que a una frágil felicidad [...] Confío en el barco humanista" (Ídem, pp. 180-181. La cursiva es nuestra).

45.. Cf. "Un humanismo bien temperado. Conversación con Tzvetan Todorov", p. 35.

Thémata. Revista de Filosofía $\mathrm{N}^{\circ} 54$ (2016) pp.: 265-280. 
la antropología y del estudio de los textos, sobre todo, de la función de la lectura y los paradójicos remedios de la escritura.

En definitiva, la obra de Tzvetan Todorov nos permite salir de las divisiones disciplinarias que impone la lógica organizacional de la enseñanza, en detrimento de la formación del espíritu y poniendo el acento en la autobiografía y las prácticas de escritura del yo. Todorov nos invita a no volver a oponer transmisión y expresión, sino muy al contrario, a ligar la autenticidad subjetiva, el descubrimiento de la alteridad y el acceso a lo universal. Por otro lado, y en una aguda sintonía, Edward Said acaba ligando su reflexión a un humanismo resistente, crítico, igualmente democrático, rompiendo las barreras impuestas por determinadas tradiciones de pensamiento a favor de una apertura total de horizontes plurales y humanos. De este modo, y con ello concluimos, si todos acabamos siendo el producto de una mentira, como ambos autores confirmarán a lo largo de sus escritos, seremos al menos y por siempre, una "mentira inventada por y para nosotros mismos". ${ }^{46}$

\section{Referencias bibliográficas}

SUBERCASEAUX, B.: "Edward Said: desde su biografía a su postura intelectual”, Revista Universum, nº 20, Vol. 1: 168 - 173, 2005.

SAID, E.: Humanismo y crítica democrática. La responsabilidad pública de escritores e intelectuales, traducción a cargo de Ricardo García Pérez, Barcelona: ed. Debate, 2006. Barcelo na: ed. Anagrama, 1996.

Cultura e Imperialismo, traducción a cargo de Nora Catelli, , "El humanismo como resistencia", El País, 2003.

GROOT, G.: Adelante, jcontradígame! Filosofía en conversación, traducción a cargo de Catalina Ginard Ferón, Barcelona: ed. Sequitur, 2008.

FIGUEROA, J.A.: "Edward Said, la periferia o el humanismo, o tácticas para trascender el postmodernismo", Íconos, núm. 18, Flacso-Ecuador, Quito, pp. 100-108.

ALI, T.: Conversaciones con Edward Said, trad. Natalia Rodríguez Martín, Madrid: Alianza ed., 2010.

TODOROV, T.: Le jardin imparfait. La pensée humaniste en France, Paris: Grasset, 1998 (El jardín imperfecto, Barcelona: Paidos, 2008).

, Nous et les autres. La réflexion française sur la diversité humaine, Paris: Seuil, 1989 (Nosotros y los otros, reflexión sobre la diversidad

46.. Cf. Said, E.: Cultura e Imperialismo, trad. Nora Catelli, Barcelona: ed. Anagrama, 1996, p. 329.

Thémata. Revista de Filosofía №54 (2016) pp.: 265-280. 
humana, traducción de Martí Mur Ubasart, Barcelona: Siglo XXI, 2001). , L’Homme dépaysé, Paris: Seuil, 1996. (El hombre desplazado, ed. Taurus, 2008).

, Vivre seuls ensemble. La signature humaine II, Paris: Points Essais, $\overrightarrow{2012}$ (Vivir solos juntos, ed. Galaxia Gutenberd, 2011). , Mémoire du mal, tentation du bien. Enquête sur le siècle. Paris: éditions Robert Laffont, 2000 (Memoria del mal, tentación del bien, traducción de M. Serrat Crespo, Península: Barcelona, 2002).

, Devoirs et délices. Une vie de passeur. Entretiens avec Catherine Portevin, Paris : ed. du Seuil, 2002 (Deberes y delicias. Una vida entre fronteras, traducción de Marcos Mayer, México: FCE, 2003).

, " Edward Saïd, le spectateur exilé», Le Monde, «Le Monde des

Livres ", mai 2008. 